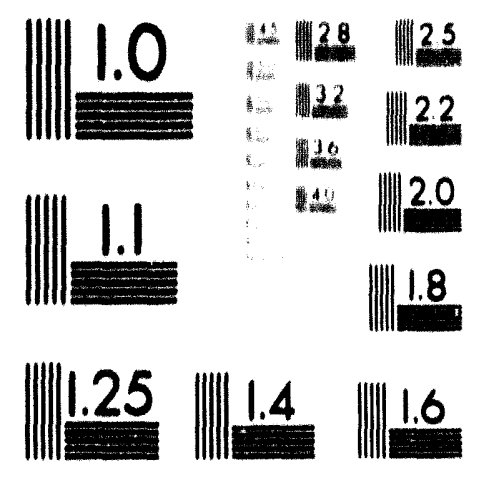





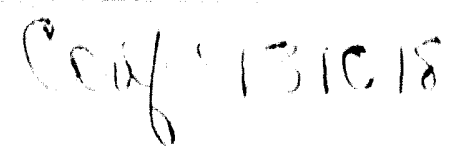

\title{
Conceptual Design of the Tokamak Radiation Shielding for the Tokamak Physics Experiment (TPX)*
}

\author{
M. J. Cole, B. E. Nelson, G. H. Jones, P. L. Goranson \\ Oak Ridge National Laboratory \\ Post Office Box 2009 \\ Oak Ridge, Tennessee 37831
}

Y. Gohar

Argonne National Laboratory

9700 South Cass Avenue, Building 205

Argonne, Illinois 60439
S. L. Liew

Princeton Plasma Physics Laboratory

P. O. Box 451

Princeton, New Jersey 08543

\section{ABSTRACT}

The tokamak radiation shielding includes the neutron and gamma shielding around the torus and penetrations required to (1) limit activation of components outside the shield to levels that permit hands-on maintenance and (2) limit the nuclear heating of the superconducting coils and cold structure. The primary design drivers are space, the $350^{\circ} \mathrm{C}$ bakeout temperature, and cost; therefore, different shield materials were used for different shield components and locations. The shielding is divided into three areas: (1) torus shielding around the vacuum vessel, (2) duct shielding around the vacuum pumping ducts and vertical diagnostic ducts, and (3) penetration shielding in and around the radial ports. The major shield components include water between the walls of the vacuum vessel, lead monosilicate/boron carbide tiles that are attached to the exterior of the vacuum vessel, shield plugs that fill the openings of the large radial ports, and polyethylene/lead/boron shield blocks for duct shielding. A description of the shielding configuration and the performance and operational requirements will be discussed.

\section{INTRODUCTION}

The Tokamak Physics Experiment (TPX) will operate with deuterium plasmas for long pulse lengths extending from 100 to $1000 \mathrm{~s}$ with the capability to be upgraded to steady state. Radiation shielding is required around the torus, pumping duct, and penetrations to (1) limit the nuclear heating of the superconducting coil set and (2) provide a biological shield for activated material inside the shield and limit activation of components outside the shield to allow hands-on access to these components. The shield will, therefore, act to reduce the size and cost of the coil cryogenic system and eliminate the need for an extensive ex-vessel remote maintenance system.

\footnotetext{
* Research sponsored by the Office of Fusion Energy, U.S. Department of Energy, under Contract No. DE-AC05840R21400 with Martin Marietta Energy Systems, Inc.
}

\section{PERFORMANCE AND OPERATIONAL REQUIREMENTS}

The tokamak shielding must be sufficient to limit neutron activation of ex-vessel components to levels that allow hands-on maintenance of these components. The total expected fluence is $4 \times 10^{22}$ deuterium-deuterium (D-D) neutrons and $8 \times 10^{20}$ deuterium-tritium (D-T) neutrons [1].

The shielding must also be sufficient to limit the maximum integrated heat load into the superconducting coils and cold structure during deuterium operation to $<5$ $k W$. The peak initial neutron source rate during deuterium operation is $5 \times 10^{16} \mathrm{D}-\mathrm{D}$ neutrons/s and $1 \times 10^{15} \mathrm{D}-\mathrm{T}$ neutrons/s. The shielding system must be capable of continuous operation at $150^{\circ} \mathrm{C}$ and withstand bakeout of the vacuum vessel at $350^{\circ} \mathrm{C}$ for indefinite periods.

\section{CONFIGURATION REQUIREMENTS AND ESSENTIAL FEATURES}

The radiation shielding consists of a thermalizing material such as water or polyethylene to slow down the neutrons, a high-cross-section material such as boron to capture the thermalized neutrons, and a high-density material to stop the gamma radiation. The shielciing is divided into the following three areas:

1. torus shielding around the vacuum vessel,

2. duct shielding around the vacuum pumping ducts and vertical diagnostic ducts, and

3. penetration shielding in and around the radial ports.

The torus shielding thermalizing material is provided by the water between the walls of the vacuum vessel. To absorb the neutrons and provide a gamma shield, the equivalent of $1 \mathrm{~cm}$ of boron carbide and $2 \mathrm{~cm}$ of elemental lead are required over the surface of the vacuum vessel. The duct shielding must include a thermalizing material equivalent to at least $20 \mathrm{~cm}$ of water, the equivalent of at least $1 \mathrm{~cm}$ of boron carbide, and the equivalent of at least 2 $\mathrm{cm}$ of elemental lead. The penetration shielding must

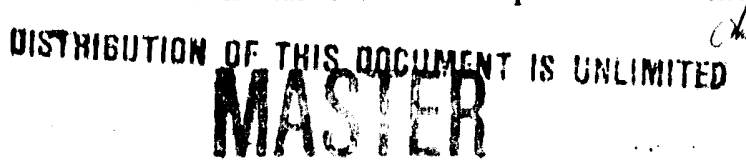




\section{DISCLAIMER}

This report was prepared as an account of work sponsored by an agency of the United States Government. Neither the United States Government nor any agency thereof, nor any of their employees, makes any warranty, express or implied, or assumes any legal liability or responsibility for the accuracy, completeness, or usefulness of any information, apparatus, product, or process disclosed, or represents that its use would not infringe privately owned rights. Reference herein to any specific commercial product, process, or service by trade name, trademark, manufacturer, or otherwise does not necessarily constitute or imply its endorsement, recommendation, or favoring by the United States Government or any agency thereof. The views and opinions of authors expressed herein do not necessarily state or reflect those of the United States Government or any agency thereof. 
include a thermalizing material equivalent to at least $25 \mathrm{~cm}$ of water, the equivalent of $1 \mathrm{~cm}$ of boron carbide, and the equivalent of at least $2 \mathrm{~cm}$ of elemental lead.

\section{DESIGN DESCRIPTION}

The primary design drivers for the radiation shielding are space, the $350^{\circ} \mathrm{C}$ bakeout temperature, and cost; therefore, different shield materials were used for different shield components and locations. Fig. I illustrates the various shield types and locations.

The torus shielding is provided by a combination of the water between the walls of the vacuum vessel and lead oxide/boron carbide tiles that are attached to the exterior of the vacuum vessel.

The vacuum vessel design provides $7.5 \mathrm{~cm}$ of water on the inboard side of the torus and $25 \mathrm{~cm}$ of water on the outboard side. This configuration practically eliminates nuclear heating on the outboard, while the inboard toroidal field (TF) coil legs recieve about $2 \mathrm{~kW}$ of neutron and gamma power.

Approximately $5 \mathrm{~cm}$ of space is required for the shielding tiles. These tiles are hot pressed from lead monosilicate and contain boron carbide powder. Lead monosilicate was selected because of its low cost and high temperature limit. The tiles are $10 \mathrm{~cm}$ square and $2.5 \mathrm{~cm}$ thick and are attached with a single titanium fastener installed using a hand-held stud welder. The general

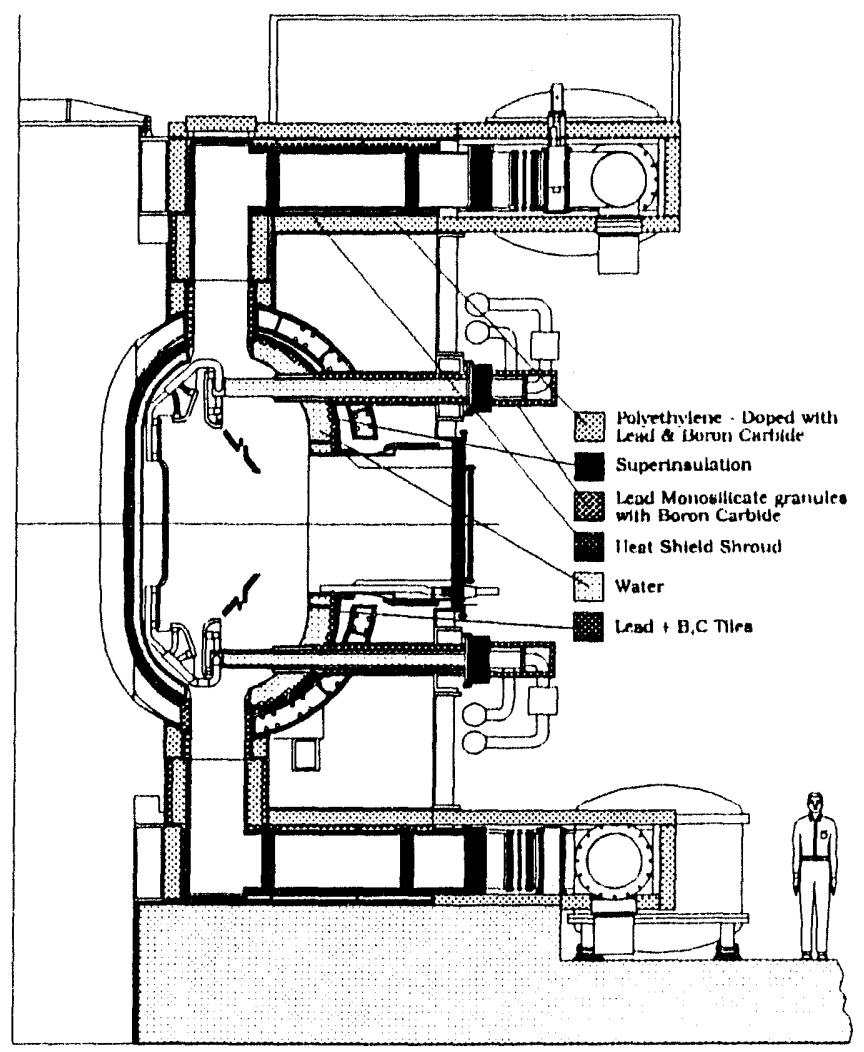

Fig. 1 Shield types and locations. configuration is shown in Fig. 2. Two layers of tiles are installed with $1.3-\mathrm{cm}$ overlap on two sides to help attenuate the gamma shine through the gaps. Approximately 30,000 tiles are required to cover the torus with a double layer.

The vacuum pumping ducts are covered with three types of shielding systems: a thin, high-efficiency system for the region that penetrates the TF coils; a gas-cooled coaxial system for the rest of the vertical part of the duct; and a more conventional system for the horizontal portion of the duct.

The vertical part of the vacuum pumping duct that penetrates the TF coils has very limited space for shield material. As shown in Fig. 3, a total of $7.5 \mathrm{~cm}$ is provided on either side of the duct, which includes $2.5 \mathrm{~cm}$ of thermal insulation and only $4 \mathrm{~cm}$ for shielding. Tungsten carbide will be attached to the duct in these areas and will be cooled by conduction to the duct wall. Radially inboard and outboard of the duct, additional shielding will be provided by filling a conforming can with lead monosilicate powder: Outside this area, the voids in the TF coil structure will be filled with a commercial mixture of polyethylene, lead, and boron in pellet form to reduce the local activation of the TF coil and structure.

The vertical part of the vacuum pumping duct outside the TF coil will be fitted with three coaxial pipes. The first anulus will be filled with superinsulation to protect the shield from the high-temperature duct. The second annulus will be filled with polyethylene blocks, sealed, and cooled with helium gas. The third, outermost annulus will be filled with a mixture of lead monosilicate and boron carbide granules.

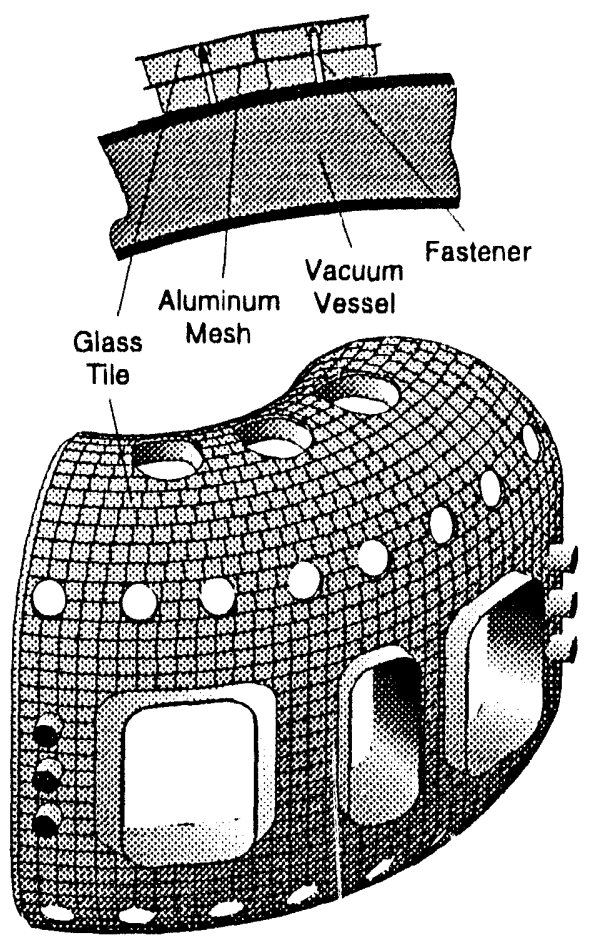

Fig. 2 Shield tile arrangement. 

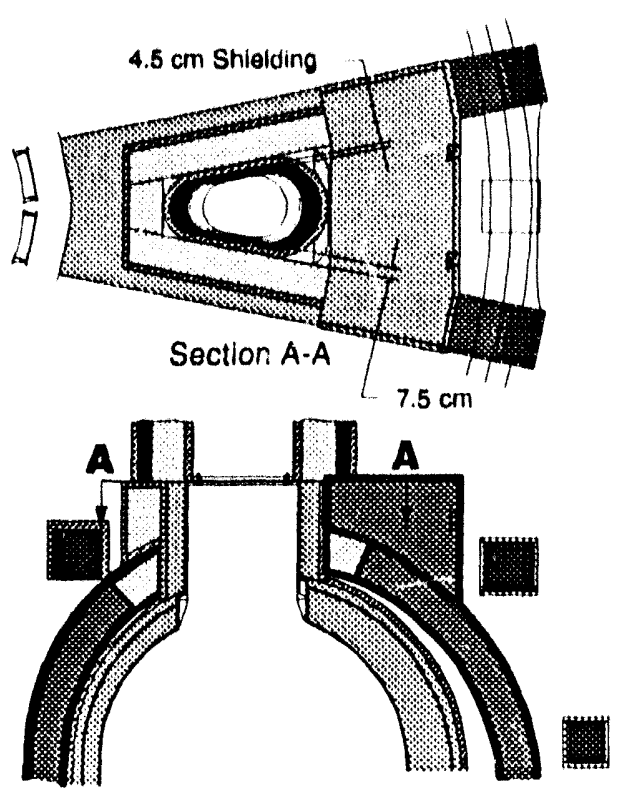

Fig. 3 Vacuum purıping duct shielding.

The horizontal portion of the vacuum pumping duct will be shielded with five layers of rectangular blocks of commercial polyethylene. The first three layers are primarily polyethylene, the fourth layer is high in boron, and the outer layer is high in lead. The polyethylene has a temperature limit of $80^{\circ} \mathrm{C}$ and must be insulated from the hot duct by thermal insulation and a helium gas-traced shroud.

Penetration shielding must be provided at all the radial ports. At most ports, large plugs are provided for the bulk of the shielding. As shown in Fig. 4, these plugs have essentially the same configuration as the vacuum vessel torus, consisting of a box made of titanium plate internally stiffened and filled with water from the vacuum vessel heating and cooling system.

Generic plug configurations are provided for each of the three main types of radial port. Each plug will be customized to suit the needs of the specific diagnostic systems that penetrate it. Shielding in ports $A, F$, and $G$ will be provided as part of the lower hybrid (LH) and ion cyclotron heating $(\mathrm{ICH})$ launcher assemblies. The ports at quadrant-to-quadrant assembly joints $(D, H, L$, and $P$ ) will also have shielding integral to the specific diagnostics. The neutral beam port at $M$ and $C$ will have plugs to prevent activation of the flange connections so that the second and third neutral beam can be added.

\section{SYSTEM PERFORMANCE AND ANALYSIS}

The shielding system is based on preliminary neutronics calculations. First, scoping studies were performed to investigate various shield compositions. Separate analyses were then performed to determine the nuclear heating and dose rates.

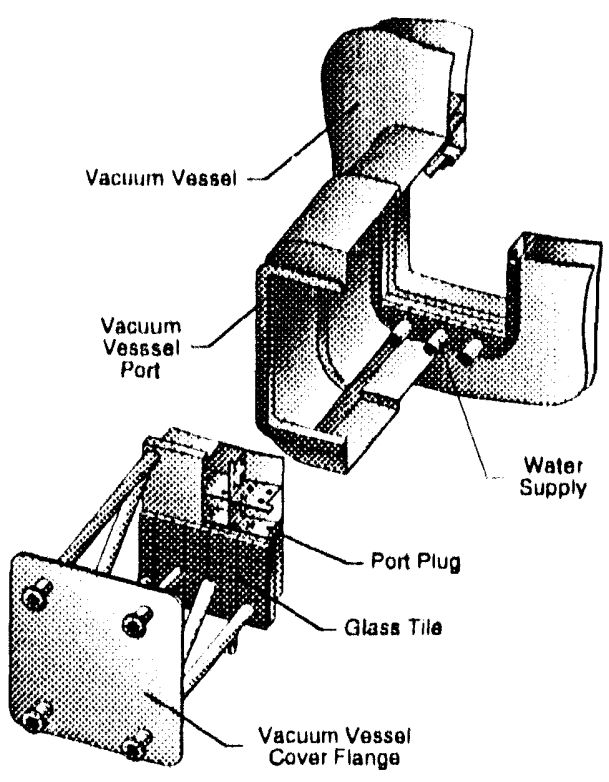

Fig. 4 Radial penetration shield plug.

The parametric variations and cost effectiveness of various compositions for the torus shielding using onedimensional models are examined in $|2|$.. It was found that because the prompt and delayed responses often represented conflicting requirements, there was no single shield composition that could be considered optimal for both requirements. Within the uncertainties of the analysis, a cost-effective shield was identified as a single-zone design based on water (or other relatively inexpensive polymers), with some lead (about $10 \%$ by volume), and a little boron carbide (about $1 \%$ by volume).

Simple estimates of the nuclear heating rates in earlier designs were given in $[3-5]$. These results were superceded by more detailed analyses reported in [6]. Most of the heating occurs on the inboard portion of the TF coil legs and around the neutral beam and vacuum pumping ducts. The summary of heat loads for the various neutron production rates is shown in Table!.

TABLE I

Nuclear Heating in Superconducting Coil Set

\begin{tabular}{|l|l|l|}
\hline Condition $^{\mathrm{a}}$ & Initial & Ultimate \\
\hline D-D neutron source rate, $\mathrm{s}^{-1}$ & $5 \times 10^{16}$ & $1.2 \times 10^{17}$ \\
\hline D-T neutron source rate, $\mathrm{s}^{-1}$ & $1 \times 10^{15}$ & $3.6 \times 10^{15}$ \\
\hline $\begin{array}{l}\text { Heating on inboard portion } \\
\text { of coil set, } \mathrm{kW}\end{array}$ & 2 & 5 \\
\hline $\begin{array}{l}\text { Heating on outboard portion } \\
\text { of coil set, } \mathrm{kW}\end{array}$ & $<<1$ & $<<1$ \\
\hline $\begin{array}{l}\text { Heating around penetrations, } \\
\mathrm{kW}\end{array}$ & 3 & 7 \\
\hline Total heat load, $\mathrm{kW}$ & 5 & 12 \\
\hline
\end{tabular}

${ }^{a}$ From [1]. 


\section{ACTIVATION AND DOSE RATES AROUND TIIE MACIIINE}

Various dose rate estimates for earlier designs are given in [5]. The preliminary activation dose map shown in Fig. 5 is taken from [7] and shows the contact dose rate 1 week after shutdown following 10 years of D-D operation. This was based on a simple three-dimensional model in which all the bays were assumed to be identical and a single shield composition was assumed throughout. The assumption for the shielding composition was a mixture of water, $1 \%$ boron carbide, and $20 \%$ lead. If the assumed composition and thicknesses can be implemented and if there are to large unshielded penetrations or undesirable materials uround, the ex-vessel radiation environment looks guite benign. The maximum dose rate outside the vessel oxcurs in the region around the radial ports and is $<10 \mathrm{mrem} / \mathrm{h}$. The regions inside the torus and neutron beam injection duct are much higher, and no hands-or access will be allowed in these areas. More detailed calculations based on the actual geometry will be required to iterate and optimize the configuration in later stages of the design.

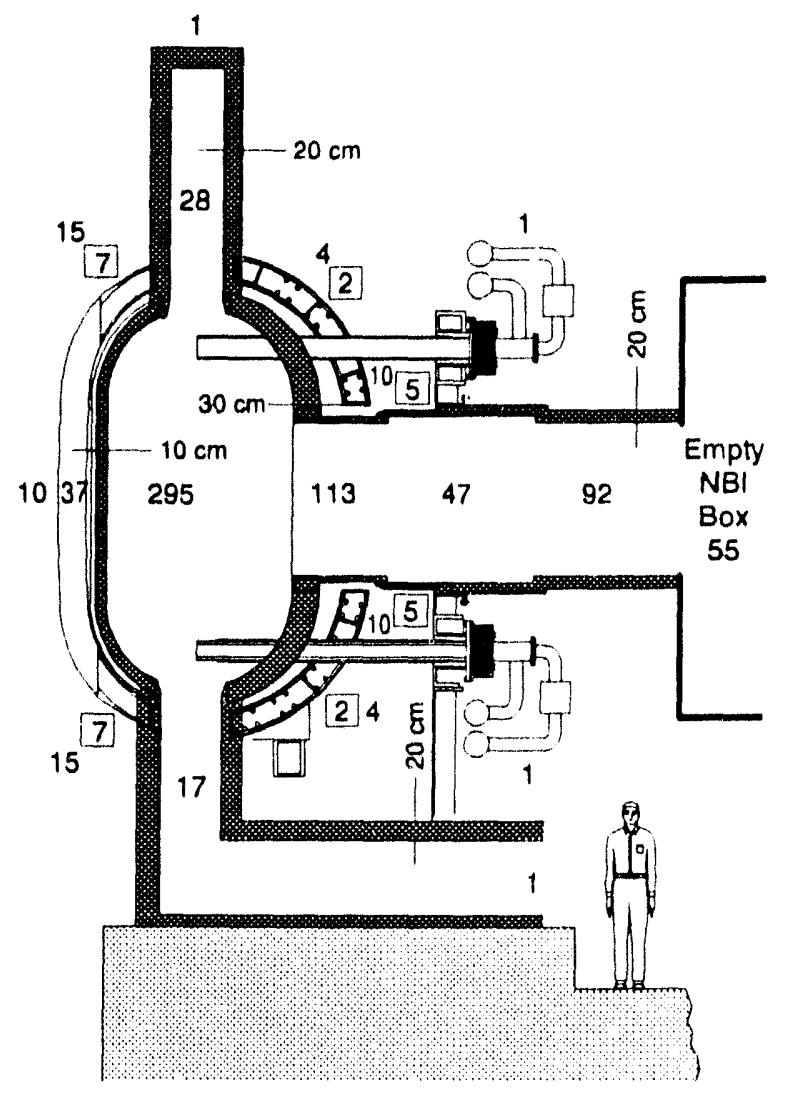

Fig. 5 Preliminary TPX dose map 1 week after 10 years of D-D operation

\section{DESIGN ISSUES ANI) FUTURE DIRECTION}

There are several issues associated with the conceptual design of the shield. The first set of issues involves the shield tiles and includes their effectiveness, fabricability, cost, and potential disposal problems. Recent calculations using a layered instead of a homogeneous model for the shield indicate that the layered shield is $50 \%$ less effective for attenuating the nuclear heating in the TF coil inboard leg. Subsequent calculations have shown that a weak solution of borated water can replace the boron in the tiles and that the lead can be eliminated, at least on the inboard portion of the torus. This option will be explored in detail during the next year. If tiles are retained in the design, research and development are planned to investigate their material properties and better quantify their cost. The disposal problem of lead monosilicate is not presently a problem, but changes in regulations could create a problem by the time TPX is decommissioned.

A second set of issues involves the effectiveness of the shield around the large ports, especially the neutral beam lines. The local nuclear heating of the TF coils and activation of ex-vessel features may require some modification of the coil and/or port shape to provide more space for the shield.

Finally, optimization of the shield composition around the puniping ducts may provide reductions in lead and boron content that would reduce cost.

\section{CONCLUUSIONS}

A conceptual design has been prepared for nuclear shielding around the TPX torus and penetrations that will limit nuclear heating in the TF coils and reduce activation outside the torus to levels that permit hands-on maintenance of ex-vessel components. Further simplifications and refinements of the design that would improve performance and reduce cost may be possible.

\section{REFERENCES}

[1] W. Reierson, TPX General Requirements Document, Princeton Physics Plasma Laboratory Projects Office, Princeton, N. J., Feb. 2, 1993.

12] S. L. Liew, Paramelric Shielding Comparison and Optimizanon Siludy for TPX, EAD-4295, Princeton Physics Plasma Laboratory Projects Office, Princeton, N J., Sept. 10, 1992.

[3] Letter, Y. Gohar to B. E. Nelson, Nuclear Heating in the TF Coils of TPX," dated Dec. 7, 1992.

14] S. L. Liew, Shielding Estimates for Superconducting SSAT, EAD4171, Princeton Physics Plasma Laboratory Projects Office, Princeton, N.J., Feb. 21, 1992.

[5] S. L. Liew, Draft Report on SSAT-S Activation and Shielding, EAD-4208, Princeton Physics Plasma Laboratory Projects Office, Princeton, N.J., April 9, 1992.

[6] S. L. Liew, 2-D Calculations of Nuclear Heating Rales in TPX TF Coils, EAD-4461, Princeton Physics Plasma Laboratory Projects Office, Princeton, N.J., Feb. 18, 1993.

17] S. L. Liew, "Preliminary TPX Dose Map," presented at the TPX Engineering Meeting. Nov. 4, 1992. 

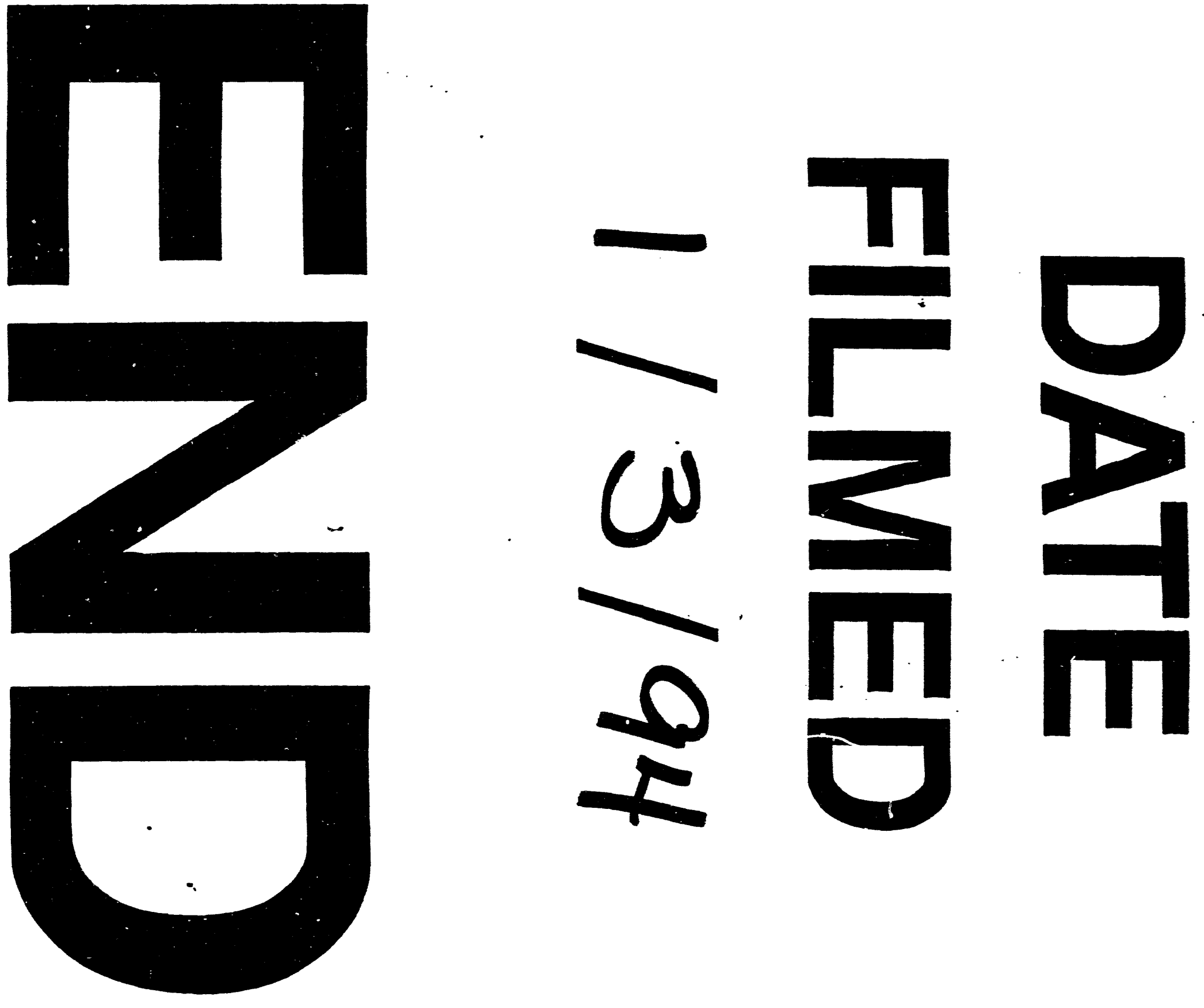

II 
